\title{
Faculty Perception, Attitude, and Readiness Towards e-Learning in Ar Rass Dental College A Comparison of Moodle and Blackboard Learning Management Systems
}

\author{
Fahad Alturise, Tamim Alkhalifah, Sami Alshmrany
}

\begin{abstract}
With advances in technology, revolutionary changes have been taking place in educational institutions. The traditional classroom method of teaching no longer fulfills all teaching outcomes. A blended teaching methodology, involving the traditional system and the addition of e-learning through the application of Learning Management Systems (LMS), provides newer opportunities to achieving the expected learning outcomes. The functionality of these systems must be studied and analyzed for proper application. This study compared the faculty experience and perception of using two of the most widely used LMS, namely Blackboard and Moodle. The results of the survey revealed that these systems help to enhance the effectiveness of teaching and learning and increase student-staff interaction. The analysis concludes that the Blackboard system of e-learning by LMS is widely preferred.
\end{abstract}

Keywords: e-learning, Learning Management Systems, Blackboard, Moodle.

\section{INTRODUCTION}

In this era, technology has been incorporated into all parts of our day-to-day activities, making it simpler and more effective to carry out tasks from small to Herculean with ease. This has also brought about a revolutionary change in the education industry by opening the doors to alternative teaching methodologies. The traditional "classroom" method of teaching face-to-face, using printed textbooks, paper-based assignments, and the manual grading of assessments has formed an education process that was, and still is, followed widely as stated in [1]. This is the most important change in using e-learning in education industry. This change teacher and students' roles to presenter and audience in the online learning. However, the current generation of students,

Revised Manuscript Received on October 10, 2020.

* Correspondence Author

Fahad Alturise *, Computer Department, College of Science and Arts in

Ar Rass, Qassim University, Ar Rass 51921, Saudi Arabia Email: falturise@qu.edu.sa

Tamim Alkhalifah, Computer Department, College of Science and Arts in Ar Rass, Qassim University, Ar Rass 51921, Saudi Arabia Email: tkhliefh@qu.edu.sa

Sami Alshmrany, Faculty of Computer and Information Systems, Islamic University of Madinah, Saudi Arabia Email: s.alshmrany@iu.edu.sa

(c) The Authors. Published by Blue Eyes Intelligence Engineering and Sciences Publication (BEIESP). This is an open access article under the CC BY-NC-ND license (http://creativecommons.org/licenses/by-nc-nd/4.0/) rightfully called "digital natives," prefer to be involved in learning methods that employ the use of various web applications and the internet. Studying using today's technologies provides them with round the clock access to interactive learning that involves case studies, group discussions, field studies, and simulations, which all fulfill their needs based on the outcome of the teaching methodologies as stated in [2]. Many higher education institutions have begun the transition from traditional teaching methods to the use of a blended learning strategy, involving both virtual teaching and e-learning utilizing Learning Management Systems (LMS). Significant investments are being made in developing LMS and promoting their use by faculty members. These systems are composed of course content organization, presentations, student assessment tools, communication tools, and functions such as group and class discussions that manage class study materials exchange and improve class activities as stated in [1]. Blackboard LLC, the provider of Blackboard Learn now called, simply, Blackboard, was brought to life by two advisors in education to create a user-friendly way to allow college faculty members to put course material on the internet. A brief overview of the evolutions of Blackboard LLC and Moodle is discussed in the literature review. These products have revolutionized the traditional teaching system by converting knowledge from tacit into codified form, thereby producing a formal representation of information as stated in [3]. Modular Object-Oriented Dynamic Learning Environment (Moodle) is an open-source system designed to create personalized learning environments. According to the Moodle website, there are 90 million users worldwide, making it the most widely used e-learning platform. As an open-source LMS, it has the advantage of allowing modifications in the product and redistributing them back to the community. However, it lacks committed support from software manufacturers, unlike other LMS, and extensive modification in the code base may affect the ability to upgrade the software as stated in [4]. Therefore, both the Blackboard and Moodle systems help faculty members to communicate easily with the students, give them access to subject materials, and introduces transparency in the grade center.

Published By:

Blue Eyes Intelligence Engineering and Sciences Publication

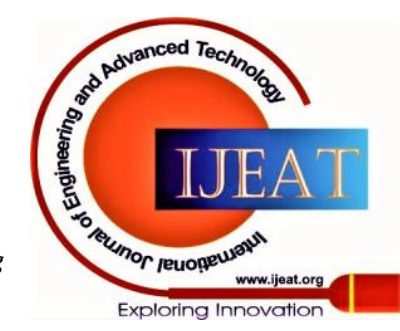




\section{Faculty Perception, Attitude, and Readiness Towards e-Learning in Ar Rass Dental College A Comparison of Moodle and Blackboard Learning Management Systems}

Therefore, it is important to understand the academic usage, facilitating conditions, and behavioral intention of the faculty members towards LMS as stated in [5].

\section{A. LiterATURE REVIEW}

An effective LMS must fulfill the following seven principles of effective teaching as stated in [6]:

1. Encourage contact between student and faculty; teachers

2. Encourage collaboration among students; well-designed discussion assignments facilitate meaningful cooperation among students.

3. Encourages active learning; students should be involved in course projects.

4. Timely feedback: instructors should offer two types of feedback - information and acknowledgment feedback.

5. Stress the need for timeliness; online courses must have deadlines.

6. Communicate quality levels, challenging tasks, sample cases, and praise for high levels of work.

7. Respect human differences giving students freedom to choose project topics that include a diversity of outlooks into online courses.

For an effective LMS system, the author in [7] applied the UTAUT model to identify the factors influencing the adoption of Blackboard by academic staff. Facilitating conditions were found to be of significance, which reveals that Blackboard enabled the users to improve their teaching and learning. However, a comprehensive overview and comparative study between Blackboard and Moodle, based on collaboration, production, and student inclusion tools, were carried out in [8]. The best and most suitable results were found to be for Moodle. Moreover, it was observed that the usage of both systems depended largely on individual preference due to different features in both systems. For this purpose, some surveys, research, and studies on the implemented systems are carried out and reported in the literature. A study on faculty use of iLearn was conducted in the American University of Sharjah to identify the purpose of use, the encouraging factors, and the pedagogical gains of the iLearn system as stated in [9]. The results showed that the static tools in the system were more widely used than the interactive tools and favored the administrative management aspect of technologies rather than the pedagogical aspects.

The author in [10] conducted both quantitative and qualitative research on the use of Moodle for teaching and learning at tertiary level education in Thailand. Moodle was found to ease the administration of courses and help make instruction delivery more cost-effective. Moodle also facilitates student-focused and anytime-anywhere approaches. However, insufficient training of the teachers negatively affected the effectiveness of Moodle. The effectiveness of Blackboard, its uses, limitations, and a comparison between Blackboard and Moodle to examine the positive points and constraints of Blackboard for better faculty data management are studied in [11]. The authors found the Blackboard system to be stronger competitively than Moodle, as it was intuitive and promoted constructivist, interactive online learning. However, the users favored should provide clear guidelines for interaction with students.

Moodle over Blackboard. To ensure the effectiveness of Moodle over Blackboard, a comparison between Moodle and alternative LMS systems in [12] was proposed to explore their strengths and limitations. The key determination is that it would be added to Qassim University to determine the best system to fulfill its requirements. The study was conducted in two phases. First, based on the features and capabilities of the LMS tools and second, based on their technical aspects. Considering the features, capabilities, and additional tools required for Qassim University, the Moodle system was found to be the most suitable LMS platform.

Furthermore, a survey based on user experience, student groups, faculty groups, and including system functionality was taken in [4] between Blackboard and Moodle. This study included a comparison of the basic functionality of each system, such as communication tools, student-to-student interaction tools, student-to-instructor interaction tools, etc. This study also preferred the Moodle-based system for users and found it more efficacious than Blackboard.

According to data from 15 institutions of the University of Wisconsin's system, it was found that the initial adoption of LMS by the faculty members was driven primarily by the need to address particular pedagogical and class management challenges as stated in [13]. Furthermore, 5\% of the participants found the system time-consuming and difficult to use, and $80 \%$ of the faculty members made use of the LMS in addition to the traditional classroom method of teaching.

With advancements in technology, different universities around the world are in pursuit of adapting e-learning for teaching and other purposes, whereas no such effort is being made by the University of Technology. Keeping in mind the struggle and investment of universities in LMS, and the rapid advancement in technology, different types of e-learning software and platforms are being launched every day. The primary competitor is Blackboard, with WebCT under consideration as well. Before going in details, a clear background of blackboard and Moodle system is discussed in paragraphs below. Note that it is not author main objective, it shows only detail knowledge of its development with its key features. Michael Chasen and Mathew Pittinsky, two educational advisors, founded Blackboard LLC in 1997 for the main purpose of providing consultation regarding technical standards of online e-learning courses. After that, IMS Global Learning Consortium partnered with Blackboard LLC, IMS being a renowned, worldwide non-profit association, which was a part of the national Educause initiative program. The key objective of Blackboard Learn, as it was called then, was to generate a suitable, user-friendly environment in which educators are able to upload proper syllabuses and courses, and students of that specific class could follow the task schedules according to a timeline preset by the teacher. Blackboard LLC needed content for the management of courses, so they merged with CourseInfo, which was a dedicated course management system created at Cornell University, and became Blackboard Inc.

Published By:

Blue Eyes Intelligence Engineering and Sciences Publication

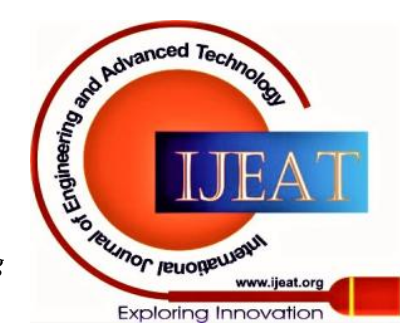


The joint venture then released their first online software for e-learning. Blackboard Inc also strategically acquired MadDuck Technologies, makers of WebCourse in a Box, who were previously very tough competitors based in Richmond, Virginia.

Within a year, Blackboard expanded with access solutions from AT\&T by acquiring CampusWide Access Solutions. Blackboard also brought commerce presence into their arena by purchasing CEI Special Teams, a branch of iCollege. Blackboard steadily started to buy up its competitors, like Prometheus, which they obtained from George Washington University in 2002. To address financial issues, Blackboard bought shares in transaction company SA cash. Blackboard was launched publicly in June 2004 after gaining around \$75 million from investing in the stock market. Blackboard partnered with WebCT in 2005, and with this expansion, they covered the online learning and course management of over $80 \%$ of North America's schools and educational establishments. Research has shown that Blackboard is today being used by almost $70 \%$ of further education locations in the United States. A 2006 sturdy showed that 60 countries, of about 12 million people, use Blackboard products. Blackboard contracts with different educational organizations, with services of online e-learning in around 2,200 locations using 12 different languages. Blackboard achieved a milestone when its value on NASDAQ doubled. With the increase in renewal rate and the client's transformation to higher levels of education, investors are positive for Blackboard as stated in [14].

Blackboard accumulates income via e-learning but also a large amount of revenue is brought in generated from license renewals. The product lines being offered by Blackboard Inc today are National Learning Environment (NLE) and National Transaction Environment (NTE) as stated in [15] and [16]. NTE performs Blackboard's transactions. Its main goal is to offer a straightforward interface and server to manage global Blackboard transactions. NTE also provides the capability of new accounts and settings. NTE is an academic offering related to course and study content. Blackboard has NLE at its core.

NTE deals with the financing of Blackboard Inc as indicated by its name, which is like a commerce suite. Also, it consists of Blackboard One and Blackboard Community System. Financing software and account details for teachers, students, and other related people are managed and provided specifically by the commerce suite, which further helps clients to easily track transactions and commerce on and off campus. Blackboards learning, content, and community systems are included in NLE. Generally, the content system of Blackboard Inc can be called the main component of NLE, which authorizes teachers to manage, create, publish, communicate, and check the performance of students. However, there are still some difficulties and issues for students to access education due to an excessive enrollment of students and highly populated classes. Moreover, not all students have access to the internet, but there is an uninterrupted provision of the internet at the university campus. But, in such a modern era, nowadays all students are trying to get smartphones where they can use the internet as stated in [17]. E-learning is being adopted and available at

Published By:

Blue Eyes Intelligence Engineering and Sciences Publication

(C) Copyright: All rights reserved. and external tools) ([36]; [42]). an open-source platform [39]. Technology, as illustrated in Fig. 1 and stated in [18]. using in to its fullest. On the other hand, Moodle based Learning Management System (LMS) is considered to be most famous in various discipline learning due to its features i.e. user friendly, open source and free download ]31[. Moodle system offer faculty feedback system outside the boundaries of classroom and adopt traditional instruction through the provision of opportunities ([35]; [43]). There are 15 different type of activities in Moodle which are divided into 7 main categories i.e. creation and sharing of a collection of data (database); organization of a set of instructional materials (lessons); delivery, collection, evaluation, and feedback about content (assignments, workshops); communication and exchange of ideas (chats, forums, news); collaboration by building shared knowledge (glossary, wikis); assessment of student learning (choice, quiz, survey, and feedback); and reusability of learning resources (SCORM,

Moodle system is categorized as instrumental for learning and teaching by many researchers (e.g., [29]; [30]; [41]) which helps in better management of course content and communication among the teacher and student both synchronously and asynchronously [37]. Moreover, the extra learning context are also transferred to acquire knowledge and skills [41]. Based on different prospective, Moodle system is classified in various studies. [34] highlighted two different functionality support by Moodle system which are resource and modules. In research digital material and resources i.e. lecture notes, power point slides, word document notes, animation and videos are uploaded whereas in modules categorized materials formed in Moodle platform.

LMS based Moodle encompasses interaction tools i.e. lessons, homework, workshops, chats, discussion forums, news, wikis, quizzes, and surveys between teachers and students [40]. [36] classified Moodle group functionality in to configured modules and external tools. In which configured modules include assignments, workshops, chats, forums, news, quizzes, and surveys whereas external tools include blogs, questionnaires, and wikis. Various researcher has different opinion on the use of Moodle. [33] point out to be slow and non-interactive but view it to be strong viewed it as a strong educational tool that provides a flexible infrastructure with the ability to add plug-ins and freely modify its code as

\section{REVIEW CRITERIA}

A questionnaire-based survey was conducted involving the teaching faculty members of the Ar Rass College of Dentistry under the Qassim University in the Kingdom of Saudi Arabia to investigate and understand their perception of and readiness for the use of Blackboard and Moodle LMS. The survey was conducted to answer the following main question: What do faculty members think about using Blackboard and Moodle LMS at Ar Rass Dental College.? This survey design was inspired by the Unified Theory of Acceptance and Use of 


\section{Faculty Perception, Attitude, and Readiness Towards e-Learning in Ar Rass Dental College A Comparison of Moodle and Blackboard Learning Management Systems}

The survey was sent to the faculty members of Ar Rass College of Dentistry at Qassim University. The total number of faculty members participating was 24 , responding to a questionnaire-based survey design with the aforementioned goals. Overall, the questionnaire was divided into sub-sections. The division of the sub-sections was based on demographic data (age, gender, academic position, and teaching year experience), a section to define the degree to which the participant believes the use of LMS supports in doing his or her job together with its ease of use, and a section to define the degree to which the participant believes the organization, technical infrastructure, and social environment support his or her use of LMS. A Likert scale was used for questions that required a narrative response. The self-evaluation is performed with criteria of age, gender, academic position, and teaching year experience, participant degree for discrimination.

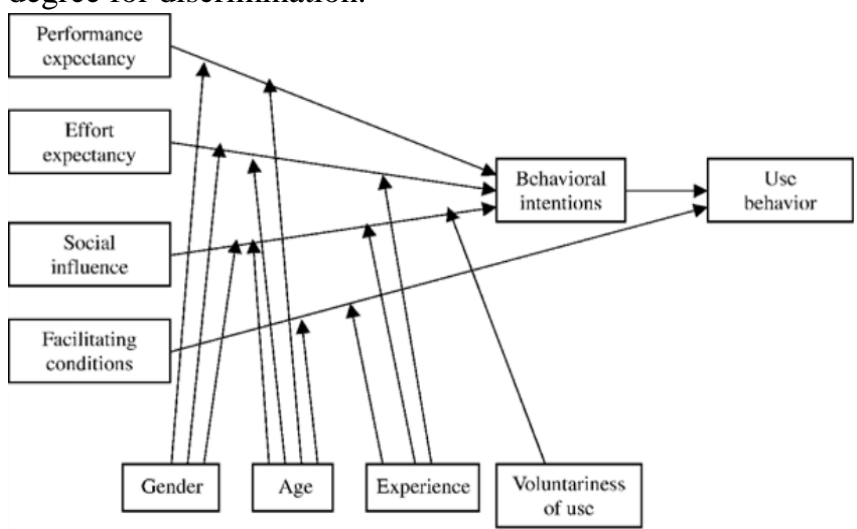

Fig. 1.The unified theory of acceptance and use of technology

\section{A. Design methodology of survey}

The survey was prepared on "Google Forms," a web-based application used to create forms for data collection purposes. No special software was required. Google stores the feedback which is input in the survey so it can be examined in detail. The forms integrate with Google spreadsheets to provide an overview of the collected data in spreadsheet form, and graphs or charts can be created as needed. All participants were instructed to answer a total of 28 questions. An email containing the survey link was sent to the college email address of the participants, and they were requested to respond within one week. The participants accessed the survey link and marked their responses.

\section{SURVEY RESULTS}

Out of the target population, 17 faculty responded to the survey in the requested time duration. All 17-faculty provided complete responses, at a response rate of $71 \%$. Since faculty were restricted to only blackboard system therefore, they were biased, and the results explained are based on teacher experience with blackboard system only. The participants had previous experience with one or more Learning Management Systems, and currently, all of them were using the Blackboard system, which made their responses to the survey questions clear and concise. The overall survey was a detailed investigation with key performance parameters such as performance expectancy, effort expectancy, facilitation condition, social influence, and behavioral intention, which are illustrated as:

\section{A. Performance expectancy}

Based on the responses of faculty members, Fig. 2 shows that about $81 \%$ believe that Blackboard enabled them to be more effective in their lecturing when compared with Moodle, which shows a $43.8 \%$ response.

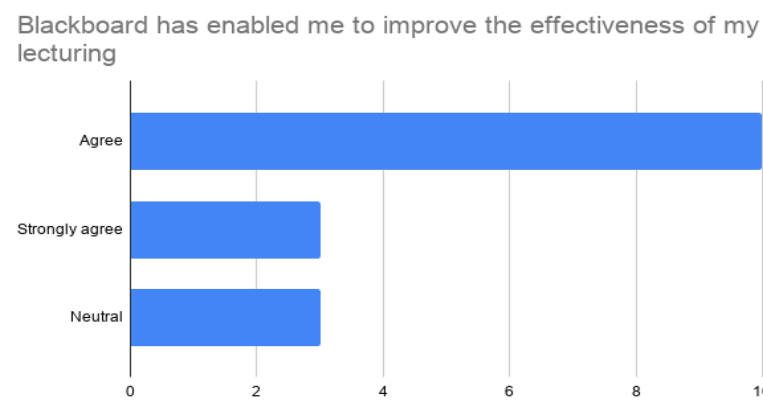

Moodle has enabled me to improve the effectiveness of my lecturing

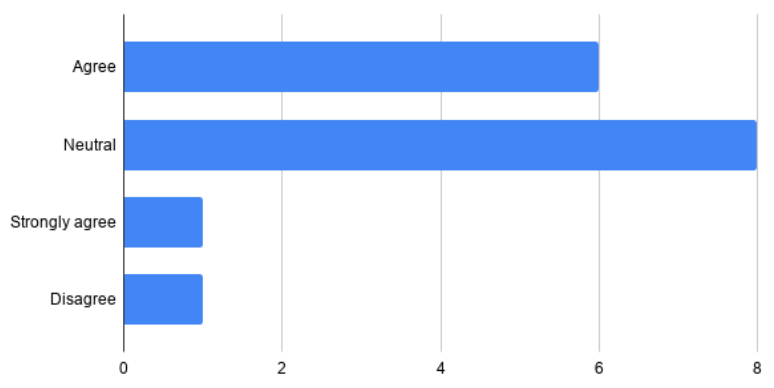

Fig. 2.Opinion that Blackboard enabled faculty members to improve the effectiveness of their lecturing, compared with Moodle

Moreover, Fig. 3 shows that about 93.8\% said they could succeed at more tasks, more quickly with Blackboard, whereas Fig. 4 illustrates that functions of communication in Blackboard increased the connection of faculty with students.
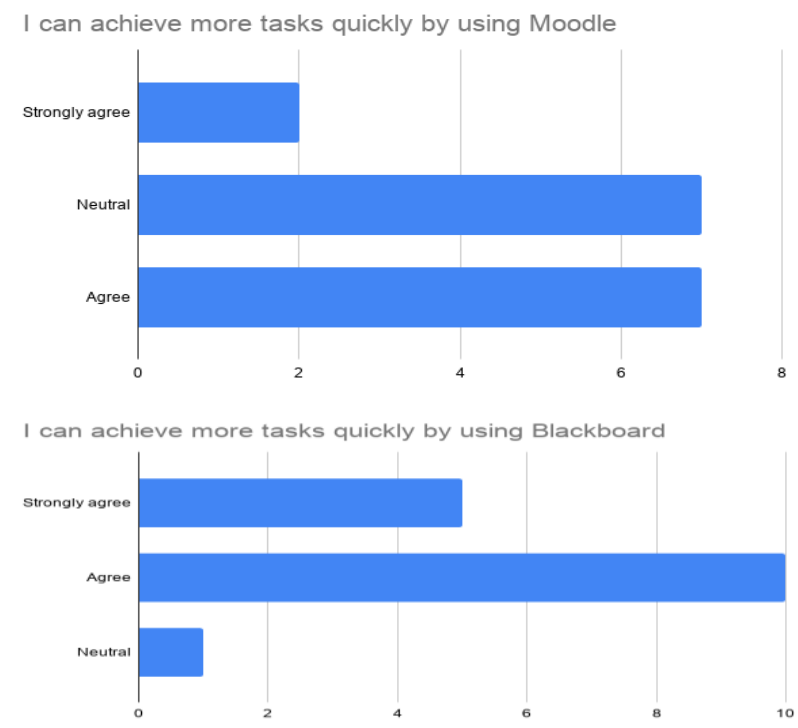

Fig. 3.They could achieve more tasks quickly using Blackboard

Published By:

Blue Eyes Intelligence Engineering and Sciences Publication

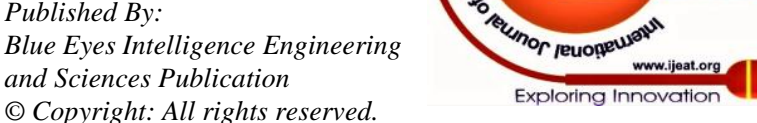


The communication tools available in Blackboard enhanced my interaction with the students

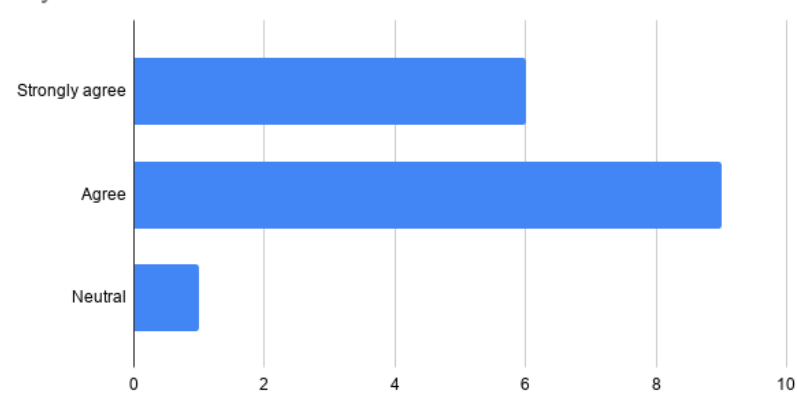

The communication tools available in Moodle enhanced my interaction with the students

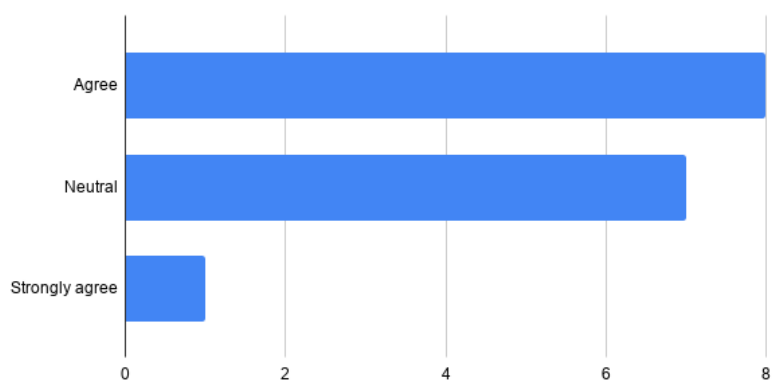

Fig. 4.Opinion that the functions of communication in Blackboard increased their connectivity with the students

\section{B. Effort expectancy}

Considering the effort expectancy, the results in Fig. 5 reveal that $43.8 \%$ believed Blackboard was easier to use than Moodle, whereas a further $43.8 \%$ of the faculty members considered the difficulty level to be the same for both the systems. Fig. 6 shows that $68.8 \%$ considered Blackboard to be more secure than Moodle. Since all 17 faculty were using blackboard system therefore, only training status of blackboard system is investigated however the aforesaid faculties have previous experience of Moodle system. Author intent to extend this training to Moodle system in the future accounting influence of student response to take part in survey.

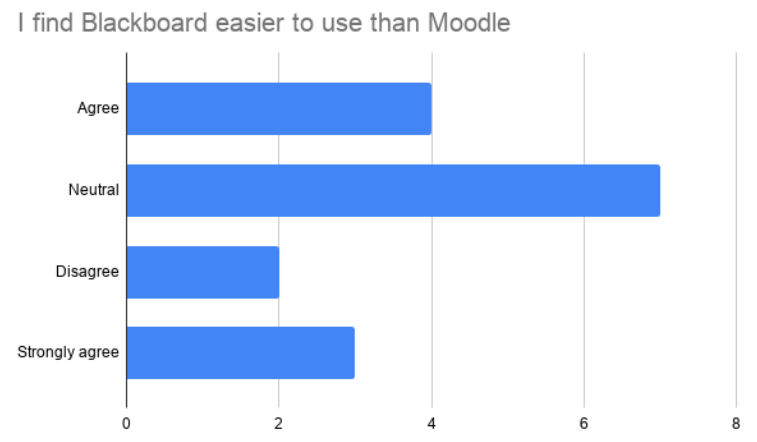

Fig. 5.Opinion that Blackboard was easier to use than Moodle

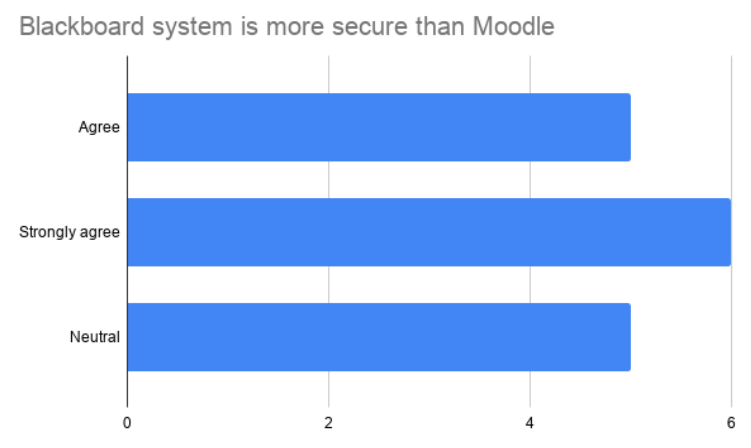

Fig. 6.Blackboard to be more secure than Moodle

\section{Facilitating conditions}

From Fig. 7, it can be clearly seen that $93.8 \%$ of the faculty strongly agree or agree that the university e-learning deanship, college IT infrastructure, and the college e-learning unit supports their use of LMS.
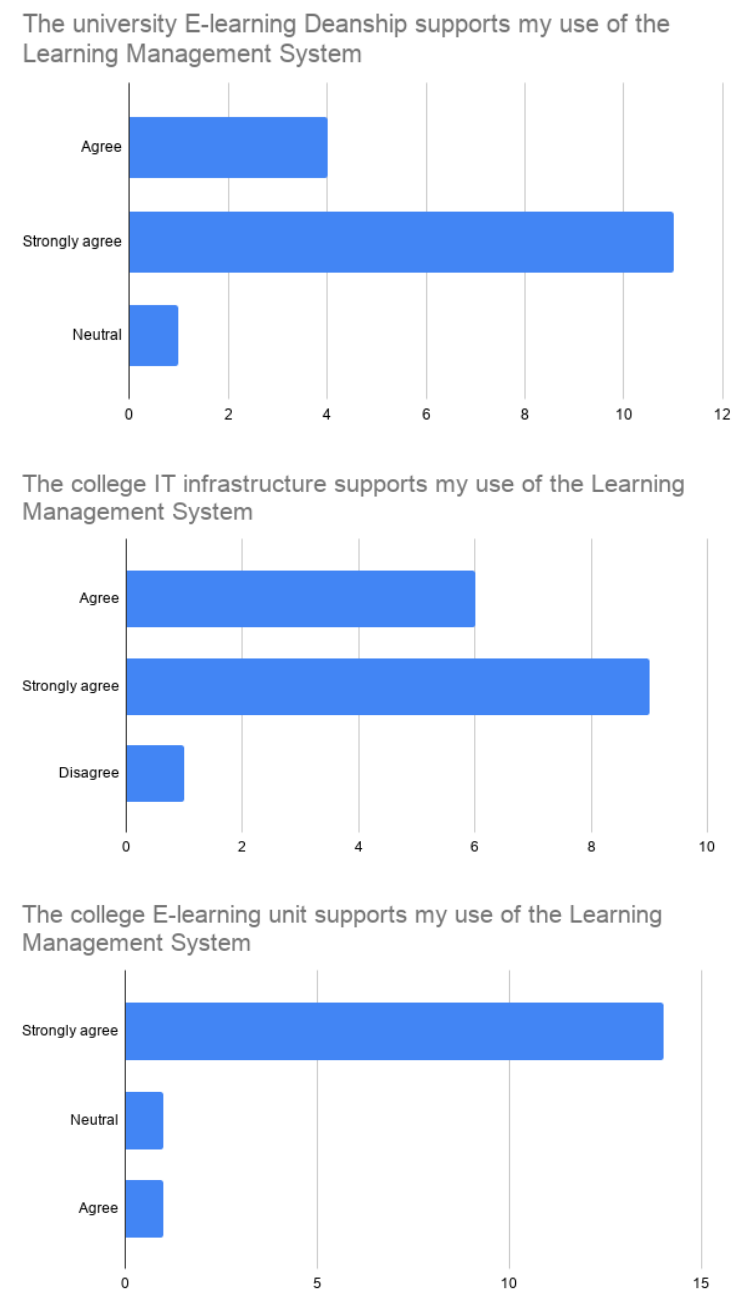

Fig. 7.The university eLearning deanship, college IT infrastructure, and the college eLearning unit support their use of LMS

Furthermore, Fig. 8 reveals that $75 \%$ of the total participant group strongly agree or agree that they have received sufficient training in the use of Blackboard. Figure 8 also shows that only $18 \%$ of participants agree they have received sufficient training in Moodle.

\section{Published By:}

Blue Eyes Intelligence Engineering and Sciences Publication

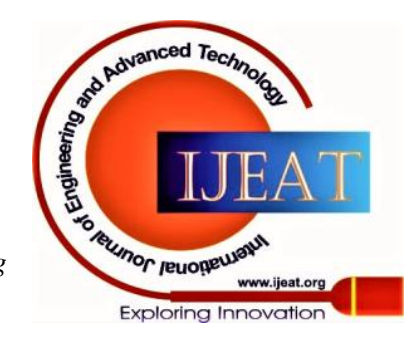




\section{Faculty Perception, Attitude, and Readiness Towards e-Learning in Ar Rass Dental College A Comparison}

of Moodle and Blackboard Learning Management Systems
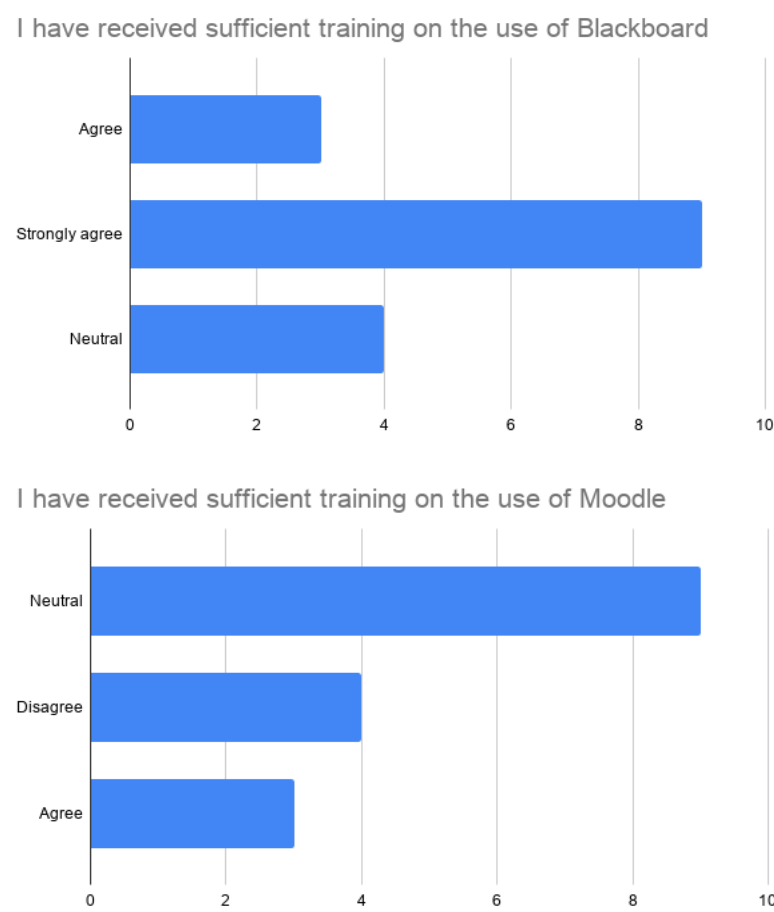

Fig. 8.Received sufficient training in the use of Blackboard, compared with Moodle

\section{Social influence}

It was found that $75 \%$ of the participant felt that their use of Blackboard was influenced by colleagues who already use it

\section{E. Behavioral intention}

Based on the survey, it was found that all faculty members prefer to continue using the Blackboard system over Moodle. This survey investigation reveals that university faculty members prefer the use of the Blackboard system in educational institutions.

\section{DISCUSSION}

This study surveyed the faculty's perceptions and attitudes towards using two different LMS systems, namely Blackboard and Moodle, including their level of satisfaction, and their preference of which LMS to use. According to the results of this study, faculty members may gain benefits from using Blackboard to teach with. The members opined that possible benefits from Blackboard include a useful way to run an e-learning course, offering the necessary practice times to teach various e-courses, enhancing variety in modern teaching methods, and promoting connectivity between them and their students as stated in [19]. The faculty members also stated that the potential benefits for students from Blackboard include the faculty providing enough guidance while teaching, motivating them to improve their teaching approach, managing course materials, and giving them opportunities to learn and receive the same classroom information as face-to-face in the familiar environment of the internet as stated in [5]. Since this survey were based on only faculty response, in order to account student opinion, the survey will be extended for student access regarding blackboard LMS. In terms of performance expectancy, the results showed that using Blackboard is more effective and useful in achieving tasks more quickly than using Moodle, and Blackboard enables more interaction with students than Moodle does. Similarly, faculty members found that Blackboard is easier to use than Moodle. Furthermore, faculty members were socially influenced by the majority of their peers to use Blackboard rather than Moodle. However, most faculty members stated that they are receiving adequate support to run both LMS systems. These findings are in line with [20], which found PE, EE, SI, and FC were significant towards Blackboard adoption.

Both Blackboard and Moodle support connectivity, self-analysis, teamwork, and communication. A literature survey suggests that both LMSs have the tools to manually create groups and assign students to each group as stated in [11]. Both systems offer connectivity functions through which participants can email their classmates, the whole class, their groups, or just the faculty. Individual and collective sharing of documents is possible in both the LMSs, which keep a history of the changes. Both systems have a chat area for communication, with tools for moderation as stated in [21]. However, Blackboard has a competitive edge over Moodle, in that it is very intuitive. Because of its e-collaborative learning tools, learning becomes enjoyable and inclusive. Downes states that e-collaborative learning provides "learners with the opportunity of social interaction and participation ... for continuous learning based on technology and modern means of communication" as stated in [22]. The effectiveness of connecting students together in showcasing knowledge and abilities has been proven by several studies. For instance, researches have emphasized the effectiveness of e-collaborative learning as stated in [23]. The review by [24], found that Blackboard's inclusive e-learning provides a platform for learners to inter-connect, which requires teachers to motivate students and strategize ahead for their academic courses and teaching programs. This direct interactive inclusivity helps learners build knowledge and new abilities and provides them with the chance of vocalizing their inquiries and leverage off each other. Therefore, Blackboard promotes constructivist, interactive online learning environments as stated in [25]. Both blackboard and Moodle LMS systems are growing in popularity among educational institutions across the globe. They have many features that assist with teaching and learning as stated in [26]. One such is their ability to support "interaction between students" and their professor "as well as among students" as stated in [27] Furthermore, it offers external learning of student outside of the classroom anywhere any time. This LMS made course content and material available for student study anywhere. This made easy access of the content for student study. Certainly, these findings confirmed that the faculty members acknowledge the effectiveness of Blackboard in the teaching process. The outcomes are in line with Hart, Bird, and Farmer (2019) [28], who stated that many teachers appreciated the virtual learning environment (VLE) in assisting them with making their teaching job more supportable than the traditional methodology.

Published By:

Blue Eyes Intelligence Engineering and Sciences Publication

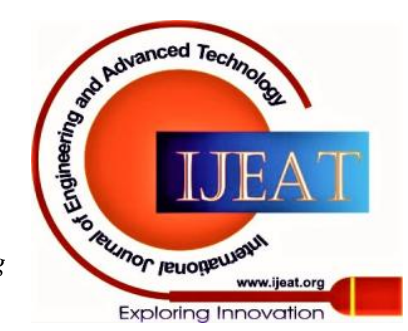


The VLE helped them organize their teaching and study materials, saved their time when amending or finding specific materials, and was easy to use.

\section{CONCLUSION}

The aim of this survey was to measure staff perceptions of two widely used Learning Management Systems, namely Blackboard and Moodle. Combined literature reviews and collected data reveals that both systems help to improve the effectiveness of lecturing, easily allow the achievement of more tasks, and enhance student-to-staff interaction. The facilitating conditions are significant in encouraging the use of LMS by faculty members. Moreover, based on the survey responses by all participants, and the data collected, analysis reveals that social influence is significant in promoting the use of Blackboard. Moreover, technical security of the system is developed and imposed within the system however based on previous experience of faculty using Moodle, Blackboard is considered to be more secure. Finally, this investigation concludes that the Blackboard system is an effective system of learning methodology if proper training is provided, and this system is the preferred choice for a Learning Management System.

\section{ACKNOWLEDGMENT}

We would like to offer thanks to the Respected Dean of $\mathrm{Ar}$ Rass Dental College, the IT department, and the e-learning unit for providing their support in conducting the study.

\section{REFERENCES}

1. Shdaifat, A., \& Obeidallah, R. (2019). Quiz Tool Within Moodle and Blackboard Mobile Applications.

2. Sarkar N, Ford W, Manzo C. (2017). Engaging digital natives through social learning. Systemics, cybernetics and informatics, 15(2), 1-4.

3. Peter Bradford et al. (2006). The Blackboard learning system: The Be All and End All in Educational Instruction, J.Educational Technology Systems, Vol. 35(3) 301-314.

4. Machado M, Tao E. (2007). Blackboard vs. Moodle: Comparing user experience of learning management systems, Proceedings - Frontiers In Education Conference.

5. Al Mulhem, A. (2020). Exploring the Key Factors in the Use of an E-Learning System Among Students at King Faisal University, Saudi Arabia.

6. Graham $\mathrm{C}$ et al. Seven principles of effective teaching: A practical lens for evaluating online courses. http://www.westvalley.edu/trc/seven.html

7. Devraj M, Irene G. (2008). Use of the Blackboard learning management system. EURASIA J Math Sci and Tech Ed, 14(7):3069-3082

8. Priyavahani S et al. (2014). A study of comparison between Moodle and Blackboard based on case studies for better LMS. Journal of Information Systems Research and Innovation: 26-33. ISSN 2289-1358.

9. Prescott D. (2003). Faculty use of the course management system ilearn at the American University of Sharjah. Learning and Teaching in Higher Education: Gulf Perspectives, 10(1)

10. Suppasetseree S, Dennis N. (2010). The use of Moodle for teaching and learning English at tertiary level in Thailand. The International Journal of Humanities, 8(6).

11. Alokluk J. (2018). The effectiveness of Blackboard system uses and limitations in information management. intelligent information management, 10:133-149.

12. AlAjlan A, Zedan H. (2008). Future trends of distributed computing systems. 12th IEEE International workshop on future trends of distributed computing systems.

13. Morgan G. (2003) Faculty use of course management systems. Educause Center for Applied Research.
14. S. Jayson, (2006) Blackboard Breaks Through, The Motley Fool, www.fool.com/News/mft/2006.

15. M. Pittinsky and T. Bell, (2005) From the Dining Hall to the Campus Bookstore to a Networked Transaction Environment: Overview White Paper, Blackboard, Inc.

16. M. Pittinsky, (2004). The Networked Learning Environment: Overview White Paper, Blackboard, Inc.

17. Sang, Y.-T., Chang, K.-E., \& Liu, T.-C. (2016). The effects of integrating mobile devices with teaching and learning on students' learning performance: A meta-analysis and research synthesis. Computers \& Education, 94, 252- 275

18. Venkatesh V. et al. (2003). User acceptance of information technology: Toward a unified view. 27(3): 425-478.

19. Zain, N. M., \& Fadil, N. F. M. (2018). Learning Management System: An Experience and Perception Study from Medical Imaging Lecturers and Scholars in a Private University. International Journal of Interactive Mobile Technologies (iJIM), 12(7), 174-180

20. Alotaibi, S. J. (2017). ICT classroom LMSs: examining the various components affecting the acceptance of college students in the use of blackboard systems. In Advances in human factors, business management, training and education (pp. 523-532): Springer.

21. Carvalho, A., Areal, N., \& Silva, J. (2011). Students' perceptions of Blackboard and Moodle in a Portuguese university. British Journal of Educational Technology, 42(5), 824-841.

22. Alzahrani, M., \& Aljraiwi, S. (2017). Effectiveness of Using Blackboard Collaborate Tools in Promoting Practical Skills among Students of the Foundation Year in e-Learning Course. British Journal of Education, 5(4), 19-53.

23. Northrup, P. (2001). A framework for designing interactivity into web-based instruction. Educational technology, 41(2), 31-39.

24. Hill, L. (2019). Blackboard Collaborate Ultra: An Online, Interactive Teaching Tool. Academy of Management Learning \& Education, 18(4), 640-642.

25. Wu, D., Bieber, M., \& Hiltz, S. R. (2019). Engaging students with constructivist participatory examinations in asynchronous learning networks. Journal of Information Systems Education, 19(3), 9.

26. Alkhaldi, A., \& Abualkishik, A. (2019). The mobile blackboard system in higher education: Discovering benefits and challenges facing students. International Journal of Advanced and Applied Sciences, 9.

27. Wells, H. (2018). Using Blackboard Collaborate to Teach Students across the State of Kentucky.

28. Hart, T., Bird, D., \& Farmer, R. (2019). Using blackboard collaborate, a digital web conference tool, to support nursing student's placement learning: A pilot study exploring its impact. Nurse education in practice, 38, 72-78.

29. Abar, C. A., \& de MORAES, U. C. (2019). Flipped Classrooms and Moodle: Digital Technologies to Support Teaching and Learning Mathematics. Acta Didactica Napocensia, 12(2), 209-216.

30. Abunabah, A. (2012). The impact of computer assisted grammar teaching on EFL pupils' performance in Jordan. International Journa of Education and Development using ICT, 8(1), 71-90.

31. Al-Ajlan, A., \& Zedan, H. (2008). Why moodle. Paper presented at the 2008 12th IEEE International Workshop on Future Trends of Distributed Computing Systems.

32. Alotaibi, S. J. (2017). ICT classroom LMSs: examining the various components affecting the acceptance of college students in the use of blackboard systems. In Advances in human factors, business management, training and education (pp. 523-532): Springer.

33. Avila, V. J. G., Hembra, N. G., Mueco, J. M., \& Zamora, F. G. (2015) Moodle and Facebook As a tool for delivering instruction and attainment of learning. Communication Research, 2(1).

34. Blin, F., \& Munro, M. (2008). Why hasn't technology disrupted academics' teaching practices? Understanding resistance to change through the lens of activity theory. Computers \& Education, 50(2) 475-490.

35. Coskun, A., \& Arslan, A. (2014). Moodling English language education. Education, 134(3), 275-281.

36. Costa, C., Alvelos, H., \& Teixeira, L. (2012). The use of Moodle e-learning platform: a study in a Portuguese University. Procedia Technology, 5, 334-343.

Published By:

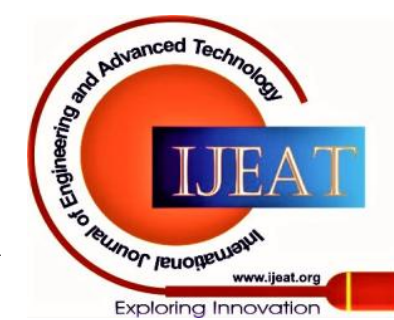


Faculty Perception, Attitude, and Readiness Towards e-Learning in Ar Rass Dental College A Comparison of Moodle and Blackboard Learning Management Systems

37. Finnegan, M., \& Ginty, C. (2019). Moodle and Social Constructivism: Is Moodle Being Used as Constructed? A Case Study Analysis of Moodle Use in Teaching and Learning in an Irish Higher Educational Institute. All Ireland Journal of Higher Education, 11(1).

38. Hart, T., Bird, D., \& Farmer, R. (2019). Using blackboard collaborate, a digital web conference tool, to support nursing students placement learning: A pilot study exploring its impact. Nurse education in practice, 38, 72-78.

39. Lopes, A. P. (2011). Teaching with Moodle in higher education. INTED 2011.

40. Mtebe, J. S., \& Kondoro, A. W. (2016). Using Mobile Moodle to enhance Moodle LMS accessibility and usage at the University of Dar es Salaam. Paper presented at the 2016 IST-Africa Week Conference.

41. Nedeva, V., Dimova, E., \& Dineva, S. (2010). Overcome disadvantages of E-learning for training English as foreign language. University of Bucharest and University of Medicine and Pharmacy Târgu-Mures, 275-281.

42. Piotrowski, M. (2010). What is an e-learning platform? In Learning management system technologies and software solutions for online teaching: Tools and applications (pp. 20-36): IGI Global.

43. Soliman, N. A. (2014). Using e-learning to develop EFL students' language skills and activate their independent learning. Creative Education, 2014.

\section{AUTHORS PROFILE}

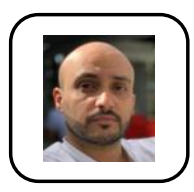

Fahad Alturise is currently working as an Assistant Professor in the Computer Department, College of Science and Arts in Ar Rass, Qassim University, Saudi Arabia. He has an experience of twelve years in the field of teaching and research. He holds a $\mathrm{PhD}$ in Information Technology from Flinders University. His primary research interests include e-learning, e-services, e-government, IOT, ICT adaption, IT security and Software Engineering. He has published 12 papers in international journals/conference proceedings $\mathrm{He}$ was a member of the Australian Computer Society (ACS) for 4 years.

Email: falturise@qu.edu.sa

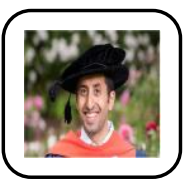

Tamim Alkhalifah is currently working as an Assistant Professor in the Computer Department, College of Science and Arts in Ar Rass, Qassim University, Saudi Arabia. In 2009, he has been admitted to a full time CS master's program at Swansea university. In 2013, he joined Flinders University, Adelaide, Australia and obtained his $\mathrm{PhD}$ in Computer science in 2018. His primary research interests include e- technologies, mobile development, mobile learning and gamification. He published several papers in the IT field.

Email: tkhliefh@qu.edu.sa

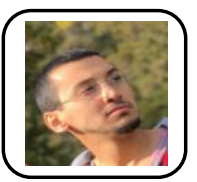

Sami Alshmrany is Assistant Professor of Information Technology since October 2018. He finished his BSc in Computer since from University of King Abdulaziz, Jeddah, Saudi Arabia in 2008. In 2009, he moved to Adelaide, Australia for further studies. He joined Flinders University, Adelaide, Australia and obtained his MSc in Information Technology in 2013. In 2018 he finished his PhD in Information Technology from Flinders University, Adelaide, Australia.

Email: s.alshmrany@iu.edu.sa

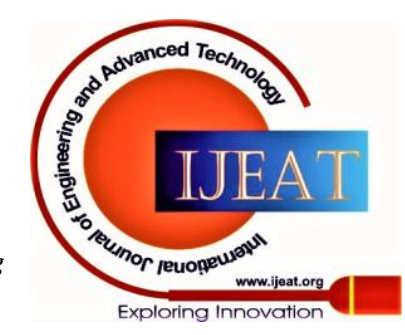

